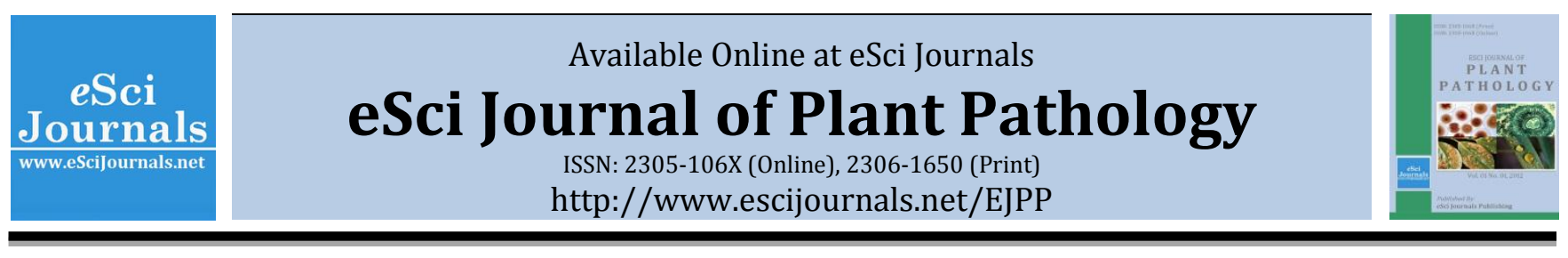

(Review Article)

\title{
ADVANCES OF BASIC MOLECULAR BIOLOGY TECHNIQUES: POTENTIAL TO APPLY IN PLANT VIROID DETECTION IN SRI LANKA
}

\author{
Y. M. A. M. Wijerathna \\ Department of Biotechnology, Faculty of Agriculture and Plantation Management, Wayamba University of Sri Lanka.
}

\section{A B S T R A C T}

Viroids are the smallest pathogens of plants. They are the cause of serious diseases on economic plants worldwide. Prevention and detection of the pathogens are the best method to reduce the economic loss from viroid infection. During last decade, genetics and molecular biology techniques have gained an increasing presence in plant pathology research. The purpose of this review is to highlight the most upgrade molecular biology techniques that have been used and studied recently. Most relevant published reports and hand skilled techniques have presented here with emphasis on suitable Viroid detection technique should be used for Sri Lanka.

Keywords: Viroids, RNA, Molecular Biology Techniques, Detection, Sri Lanka.

\section{INTRODUCTION}

Viroids are the smallest plant pathogens known, with single stranded, circular, covalently closed, autonomously replicating RNA as genomes (Flores et al., 2005). Viroids are small circular molecules, a few hundred nucleotides long, with a high degree of secondary structure and do not code for any polypeptides and replicate independently of any associated plant virus (Roger Hull, 2009).

Viroids are classified in to two families, Pospiviroidae, composed of species with central conserved region (CCR) and without hammer head ribozymes and Avsunviroidae, composed of members lacking CCR but able to self-cleavage in both polarity strands through hammer head ribozymes (Flores et al., 2005). With viroids thus defined by their molecular characteristics, diagnosis of a suspected pathogen as a member of this group must therefore rest on proof that a viroid-like molecule is present and responsible for the disease under investigation. Four important points should be considered (Hanold, D., 1993):

1. Designing an extraction method which is efficient

* Corresponding Author:

Email: akila.mw.yapa@gmail.com

(C) 2012 eSci Journals Publishing. All rights reserved. and suitable for potential viroid and optimized for each different host species, because most viroids such as Coconut Cadang Cadang Viroid (CCCVd) and Coconut Tinangaja Viroid (CTiVd) in palms, appear to be present in their host in very low concentrations. Also the nature of the host tissue may be such that difficult to extract the viroid RNA.

2. Appropriate method to storage the extracted RNA by avoiding enzymatic RNase degradation.

3. Viroid purification from ubiquitous presence of small cellular nuclear acids.

4. Study appropriate inoculation methods as the final proof that an isolated viroid is the cause of a disease.

A good understanding of viroids and viroid infection is necessary for practicle purposes such as their detection in field and plantation crops and control of their spread through quarantine or genetic engineering (Ding, B. and Itaya, A., 2007). In agricultural country like Sri Lanka where Coconut, Arecanut, Potatoes and Citrus are grown and import some of related palms, potatoes, citrus fruits etc. it's an important point to studying and develops the basic principles of diagnostic procedures of RNA viroids with economical methods and get the maximum use of molecular biology techniques to 
quarantine procedures of viroid diseases to this island home.

Since viroids produce no specific proteins, the immunological methods applied so successfully to viruses cannot be used for the diagnosis of diseases that they cause. Similarly, because no characteristic particles can be detected, electron microscopic techniques are inappropriate. For these reasons diagnostic procedures have been confined to biological tests, gel electrophoresis, PCR, and nucleic acid hybridization tests (Roger Hull., 2009). In here highlighted the most upgrade basic molecular biology techniques that have been used and studied recently.

\section{METHODS}

\section{Nucleic Acid Extraction:}

There is no any universal procedure for extraction of nucleic acid from plants. Mainly because of many plants have a cocktail of organics in tissue which interfere with the isolation of nucleic acids. To overcome this difficulty a set of extraction buffers are used one which should provide good nuclear acid suitable for diagnose the sample for viroids.

In order to limit contamination by RNAses, general sterile working practices must be adopted and clean gloves should be worn at all times. Diethylpyrocarbonate (DEPC) can be used to treat the water, stock solutions by adding $0.1 \%$. To prepare sterile RNAse free metal and glass ware supplies wrap I foil and bake at $200^{\circ} \mathrm{C}$ for $3-4 \mathrm{hr}$ : autoclaving at $121^{\circ} \mathrm{C}$ is not sufficient. Also can be treating with $2 \mathrm{M} \mathrm{KOH}$ in $90 \%$ ethanol. The working area should be in cool in condition and clean which might carry RNAse contamination. Here examples of some protocols successfully used for the extraction of CCCVd, Citrus Viroids and related viroids from palm and horticultural crops are described.

1.1) CTAB Extraction: For the first sample $1.5 \mathrm{ml}$ of CTAB solution can be added to the sample bag (solution should be at ambient temperature) and crushed the extraction by using either hammer or roller. When all the tissues are crushed, they were pushed to the bottom of the bag and let sit upright at ambient temperature to allow $30 \mathrm{~min}$ incubation. Then move all the tissues to one bottom corner and squeezed the tissue to separate the slurry in to other corner. By using wide bored pipette $900 \mu$ l of slurry was removed and added to microfuge tube. $600 \mu \mathrm{l}$ of Phenol, Chloroform, iso-amyl Alcohol (Phenol: CA; 1:1) after step of vortex mixture was allowed to centrifugation $(10000 \mathrm{~g}, 15$ min) at ambient temperature. $800 \mu$ of upper aqueous phase was removed to a new microfuge tube and $600 \mu \mathrm{l}$ of CA (Chloroform: iso-amyl Alcohol added: 24:1). After $15 \mathrm{~s}$ vortex allow to centrigugation $(10000 \mathrm{~g}, 10 \mathrm{~min}$ ). $750 \mu \mathrm{l}$ of upper aqueous phase was removed to a new microfuge and $0.9 \mathrm{vol}(600 \mu \mathrm{l})$ of iso-propanol was added and mixed gently. Then the solution was incubated at $-20^{\circ} \mathrm{C}$ for $3-4 \mathrm{hr}$ (overnight also possible). Precipitated nucleic acid was allowed to get pellet by centrifugation (10000g, 10min) and supernatant carefully discarded. By adding $700 \mu \mathrm{l}$ of $70 \%$ ethanol pellet was washed by gently mixing for more than one hour and nucleic acid was allowed to get pellet by centrifugation $(10000 \mathrm{~g}, 10 \mathrm{~min})$ at ambient temperature. Supernatant was carefully discarded and pellet was air dried.

1.2) K/SDS Extraction: The total nucleic acid of infected sample was extracted by the sodium dodecyl sulfate (SDS)-Potassium acetate method (Dellaporta et al., 1983). 50mg of sample were ground in $2 \mathrm{ml}$ of extract buffer solution (0.1 M Tris-HCl [pH 8.0], $0.5 \mathrm{M}$ $\mathrm{NaCl}, 1 \%$ 2-mercaptoethanol, 0.05 M EDTA [pH 8.0], $1.25 \%$ SDS, 3.3\% PVP, and $1.25 \mathrm{M}$ potassium acetate) $(40 \mathrm{v} / \mathrm{w})$ and stirred thoroughly. The solution was centrifuged for $10 \mathrm{~min}$ at $15,000 \mathrm{~g}$, and the supernatant was obtained. A half volume of 2-propanol was added to the supernatant, the solution was mixed, it was then centrifuged for 10 minutes at $15,000 \mathrm{~g}$, and the supernatant was obtained. Equal amounts of $99.5 \%$ ethanol and 1/10 volume of $3 \mathrm{M}$ sodium acetate were added to the supernatant, mixed, and the total nucleic acid was precipitated. The total nucleic acid was dissolved in $50 \mu \mathrm{l}$ of $0.1 \mathrm{TE}$ ( $\mathrm{pH} 8.0$ ).

1.3) Phenol Extraction: For the first sample $1.5 \mathrm{ml}$ of Phenyl ( $\mathrm{pH}$ 8.0) solution can be added to the sample bag (solution should be at ambient temperature) and crushed the extraction by using either hammer or roller. When all the tissues are crushed, they were pushed to the bottom of the bag and let sit upright at ambient temperature to allow $30 \mathrm{~min}$ incubation. Then move all the tissues to one bottom corner and squeezed the tissue to separate the slurry in to other corner. By using wide bored pipette $900 \mu$ l of slurry was removed and added to microfuge tube. $600 \mu \mathrm{l}$ of PCA after step of vortex mixture was allowed to centrifugation $(10000 \mathrm{~g}$, $15 \mathrm{~min}$ ) at ambient temperature. $800 \mu \mathrm{l}$ of upper 
aqueous phase was removed to a new microfuge tube and $600 \mu \mathrm{l}$ of CA. After $15 \mathrm{~s}$ vortex allow to centrigugation $(10000 \mathrm{~g}, 10 \mathrm{~min}) .750 \mu \mathrm{l}$ of upper aqueous phase was removed to a new microfuge and $0.1 \mathrm{vol}(75 \mu \mathrm{l})$ of Sodium Acetate was added and mixed gently and $0.9 \mathrm{vol}(750 \mu \mathrm{l})$ of iso-propanol was added and mixed gently. Then the solution was incubated at $20^{\circ} \mathrm{C}$ for $3-4 \mathrm{hr}$ (overnight also possible). Precipitated nucleic acid was allowed to get pellet by centrifugation (10000g, 10min) and supernatant carefully discarded. By adding $700 \mu \mathrm{l}$ of $70 \%$ ethanol pellet was washed by gently mixing for more than two hour and nucleic acid was allowed to get pellet by centrifugation $(10000 \mathrm{~g}$, $10 \mathrm{~min}$ ) at ambient temperature. Supernatant was carefully discarded and pellet was air dried.

1.4) LiCl Extraction: According to Murcia et al.,2008, plant tissue (5 g) stripped from young shoots was reduced to powder in liquid nitrogen and homogenized in $5 \mathrm{ml}$ of extraction buffer $(0.4 \mathrm{M}$ Tris- $\mathrm{HCl} \mathrm{pH} \mathrm{8.9;1 \%}$ $(\mathrm{w} / \mathrm{v})$ SDS; 5 mM EDTA pH 7.0; 4\% (v/v) 2mercaptoethanol) and $15 \mathrm{ml}$ of water-saturated phenol. The total nucleic acids were partitioned in $2 \mathrm{M} \mathrm{LiCl}$ and the soluble fraction was concentrated by ethanol precipitation and resuspended in $300 \mathrm{ml}$ of TKM buffer (10 mM Tris-HCl; $10 \mathrm{mM} \mathrm{KCl;} 0.1$ mM MgCl2 pH 7.4).

1.5) Guanidine Extraction: According to Wijerathna, Y.M.A.M., 2012, approximately $0.2 \mathrm{~g}$ of plant tissue was homogenized with $2 \mathrm{ml}$ of the extraction buffer in a heavy-duty thick plastic bag using a hammer on a wooden surface. $0.7 \mathrm{ml}$ of the homogenate was transferred to a $1.5 \mathrm{ml}$ microcentrifuge tube containing $0.07 \mathrm{ml} 20 \quad \% \quad$ (wt/vol) sarkosyl (N-LauroylSarcosine).The tube was then incubated at $70^{\circ} \mathrm{C}$ for 10 minutes with agitation. $0.4 \mathrm{ml}$ chloroform/isoamyl alcohol $(24: 1 \mathrm{v} / \mathrm{v})$ were added and mix vigorously for 30 seconds and centrifuge at $4^{\circ} \mathrm{C}$ for $15 \mathrm{~min} .400 \mu \mathrm{l}$ of the upper phase was transferred to a clean tube containing $30 \mu$ l Silica Milk (unpublished data) mix and was added $380 \mu \mathrm{l}$ ethanol, mixed well and spin at $8 \mathrm{k}$ for one min. The pellet was re-suspended in $600 \mu \mathrm{l}$ Wash 1 , spin at $8 \mathrm{k}$ for 30 seconds. The top phase was removed and pellet was washed twice in Wash 2 and each time spin as above. Final spin was given for two min at full speed to remove any traces of ethanol from the tube. Silica milk was dried at $65^{\circ} \mathrm{C}$ for 30 seconds or at room temperature for longer.70 $\mu \mathrm{l}$ TE buffer $(\mathrm{pH}$ 8.5) was added and mixed and incubates at $65^{\circ} \mathrm{C}$ for one min, and mixed again and spin at $4{ }^{\circ} \mathrm{C}$ for $30 \mathrm{~min}$ at full speed. The aqueous phase was transferred to a new eppendorf tube and stored at $-20^{\circ} \mathrm{C}$.

2. Gel Electrophoresis: A gel electrophoresis technique for the rapid and sensitive detection of viroids and virusoids is described. Starting from plant material, a typical analysis requires less than 5 hours. Viroid concentrations as low as $800 \mathrm{pg} / \mathrm{g}$ tissues can be detected unambiguously without the use of radioactivity, organic solvents, or highly specialized laboratory equipment. The sensitivity may be further increased by introducing additional purification steps (Schumacher et al., 2008). Due to their characteristic molecular properties, viroids migrate in most gel systems with a mobility less than that expected for molecule of their molecular weight. Common, singlestranded, linear RNA size markers are therefore not suitable for estimation of viroid molecular weight, and interpretation of gel patterns is often difficult even in comparison with known viroid markers. If linear viroid forms are present, their size can be estimated in denaturing gels by comparison with linear RNA markers (Hanold, D., 1993).

2.1) Return-Polyacrylamide Gel Electrophoresis (RPAGE): Return-polyacrylamide gel electrophoresis (RPAGE) is one of the methods used for the detection of viroids, in particular Chrysanthemum stunt viroid (CSVd) and Potato spindle tuber viroid (PSTVd). The method is based on temperature-related conformational changes of the circular single-stranded RNA molecule. This results in a characteristic electrophoretic behaviour, providing a clear separation between the viroid and nucleic acids of the plant (Figure 1). Since the description of R-PAGE, several modifications of the procedure have been published (Roenhorst et al., 2000). The vertical electrophoresis system was replaced by a horizontal one, which was easier to handle (Schroeder et al.,1989).

2.2) Two Dimensional Gel Electrophoresis (2DPAGE): In this system, a whole track from a nondenaturing gel is cut out and placed across a gel containing $8 \mathrm{M}$ urea and then electrophoresed at a $90^{\circ}$ angle to its first run (Schumacher et al. 1983). The system developed by Feldstein et al., (1997) in contrast relies upon an increase in the degree of cross linking rather than acrylamide concentration to preferentially retard migration of circular molecules. Because the buffer conditions are identical, both dimensions can be 
cast before the sample applied. The gel is simply rotated $90^{\circ}$ between the first and second dimension.

This has the advantage that the complete molecular range can be screened for possible viroids, rather than having to cut out a certain area. This is especially advantageous when looking for unique nucleic acids associated with an unknown pathogen. Gel strengths can be varied to get good separation in both dimensions. It is also possible to reverse the sequence of conditions that is, denaturing gel as the first dimension and non-denaturing as the second. This may result in less background if samples are not completely clean, and it will make staining of the second gel with ethidium bromide possible for preparative applications, since the native molecules will stain much more strongly with this method than denatured viroids. Running the second gel at a $90^{\circ}$ angle prevents trapping of small amounts of viroid by excess linear nucleic acids since viroid molecules do not have to pass through a gel area contaminated with other molecular species (Hanold, D., 1993).

If used in connection with a sensitive detection method (silver stain or molecular hybridisation), the twodimensional PAGE system is a sensitive and definitive test for the presence of small, circular nucleic acids in a preparation, and is thus a powerful tool in the search for viroids (Figure 2 and Figure 3) (Hanold, D., 1993).

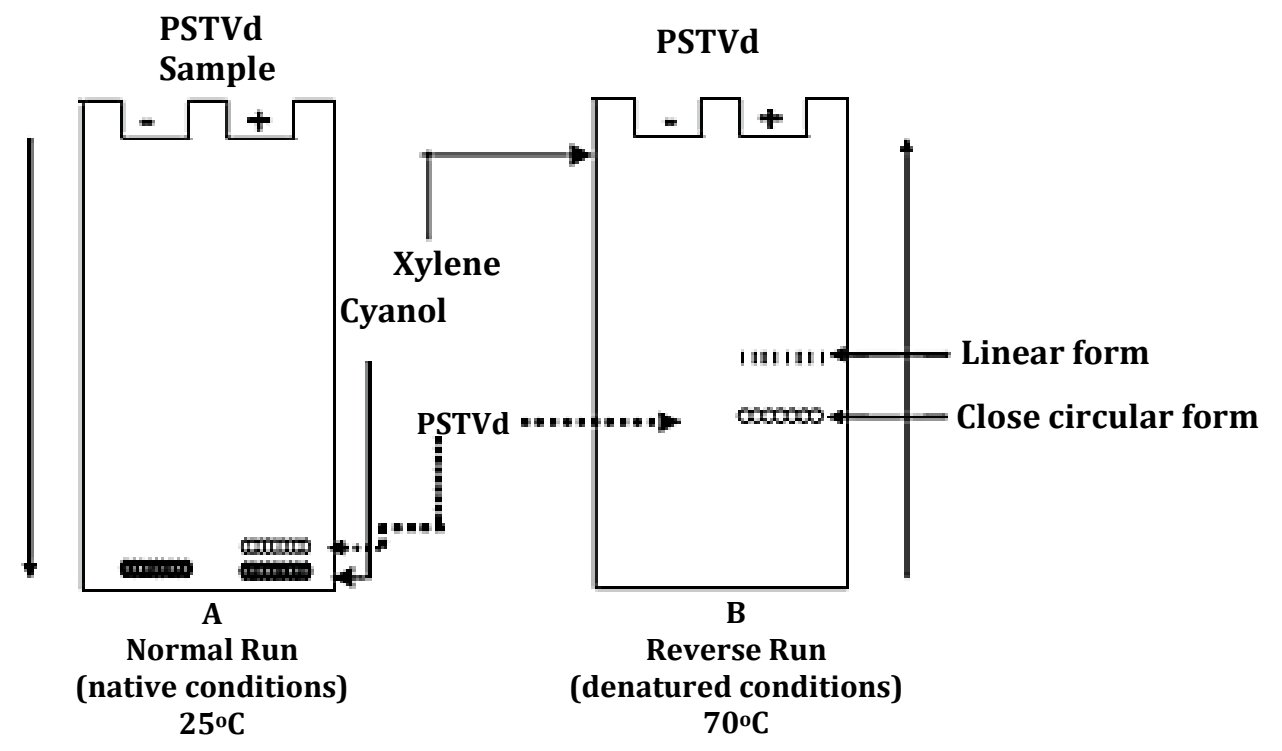

Figure 1. R-PAGE technique for detection of viroid in infected plant (+) compared with healthy plant (-) (A) Native condition (B) Denatured condition

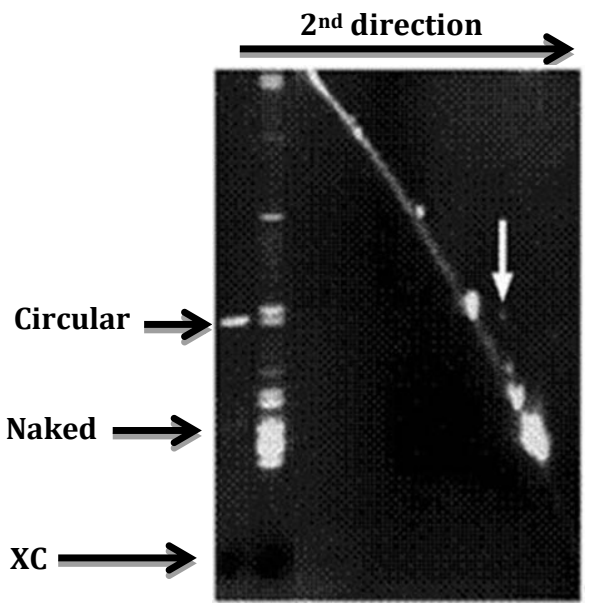

Figure 2. 2D-PAGE technique for detection of viroid. White arrow shows intact circular RNA viroid after $2^{\text {nd }}$ electrophoresis. XC: xyline cyclone dye
Figure 3. 2D-PAGE technique for detection of viroid. White circle area shows intact circular RNA viroid after $2^{\text {nd }}$ electrophoresis. 
3. Silver Staining: After electrophoresis the gel can be transferred in to a tray and RNA extract was fixed to the gel matrix in $10 \%$ trichloroacetic acid for 10 minutes on top a shaker and gel was washed twice with distilled water (DW). Gel was stained with $0.19 \%$ silver nitrate for 45 minutes on top a shaker and immediately the stained gel was washed with DW. CCCVd bands were visualized by adding $1 \mathrm{X} \mathrm{NaBH}_{4}-\mathrm{NaOH}$ and 2-3 drops of formaldehyde and stained gel was washed with DW. The stained gel was soaked in $\mathrm{Na}_{2} \mathrm{CO}_{3}$ solution to enhance bands resolution (Wijerathna, Y.M.A.M. 2012).

\section{DISCUSSION}

The CTAB extraction is excellent for isolation of DNA. This procedure provides a high yield of DNA and it is applicable to most plant species. CTAB procedure is not recommended for isolation of RNA only. Extraction procedures using CTAB solutions generally include an incubation of crushed tissue in the CTAB solution at $60^{\circ} \mathrm{C}$. However we have understood that this incubation is not by experience. High temperature incubation also greatly reduces the yield of RNA.

K/SDS extraction is somewhat similar to CTAB extraction. This protocol describes a method for RNA purification by sodium dodecyl sulfate (SDS) solubilization. It is of wide utility and is used routinely to deproteinize RNAs in biological material that has been solubilized in SDS, an ionic detergent that dissolves membranes, disrupts protein-nucleic acid interactions, and inactivates ribonucleases. Here, in addition to DNA, a good quality RNA is extracted. High potassium concentration with SDS is used to precipitate proteins away from nucleic acid instead of using an extraction with phenol (Richard, H. 1998).

By using phenol extraction method, less DNA and RNA is obtained in comparison to other procedures (unpublished data) but the RNA is intact where represented by strong, distinct gel fractionated fragments in gels. These extracted RNA is not good for cDNA preparation or PCR analysis.

The LiCl precipitation step selectively separates the RNA from other cellular macromolecules including sheared DNA, proteins and some polysaccharides. Inclusion of potassium salt precipitation step facilitates selective precipitation removal of positively charged polysaccharides (Wilkins et al., 1996).

Guanidine is a chaotropic salt that effectively denature an inactivate proteins, even RNAses (Randles, J., pers. comm.). Within this chaotropic salt rich environment silica compounds are capable of specifically binding DNA and RNA molecules, whilst contaminating lipids and proteins have only moderate affinity for these compounds and may be readily washed away. Alternatively, by chemically changing the nature of silica matrix, the matrix may be transformed to specifically bind contaminating protein vegetable polysaccharides instead of nucleic acids. Nucleic acid adsorption to silica matrices is actually enhanced in acid $\mathrm{pH}$ and high salt concentrations, with the consequence that a buffer solution containing an elevated $\mathrm{pH}$ and low salt conditions may be used to elute bound nucleic acid from silica matrix (Boom et al., 1990; Tian et al., 2000).

For cells enriched in RNAse even those that are not, homogenization in lysis buffers consisting of guanidium thiocynate (GuTC) or guanidium hydrochloride (GuHCl) is widely accepted. At a working concentration of about 4-6 $M$ (in water) it is an excellent inhibitor of RNAse activity during purification of nucleic acids from cells and whole tissue samples, GuTC is a stronger protein denaturant than $\mathrm{GuHCl}$ and is the denaturant of choice for the preparation of RNA from be considered fairly hostile considerations (Robert E.F., 1998).

By understanding basic principles and function of these chemicals, it is possible to get combine these different methods like, PCA extraction is the method of choice for preparing cytoplasmic RNA from tissue culture cells where solubilization in SDS is easily achievable.

Usually samples are fractionated in native gels where the molecules maintain the most stable base paired and secondary structure state. In native gels linear and circular molecules have the same migration pattern due to the internal base pairing in their sequence. Particularly for the RNA which often has a high degree of secondary structure, in native gels doesn't give an accurate estimation of size.

This difficulty with RNA structure is overcome by including in in gels denaturing agents such as formamide, formaldehyde or urea, which are distruptive the base pairing and secondary structure (Richard et al., 1998).A 2D-PAGE separation of RNA involves of a sample in a non-denaturing gel for the first dimension, followed by further separation in a second dimension in a denaturing gel. This method can be used to detect circular viroids. 


\section{CONCLUSION}

Viroid control is critical for the commercial agriculture: quarantine, sanitation and certification programs. These programs require large numbers of indexing tests, and these tests must be as sensitive and as economic as possible. The use and study further on basic molecular biology techniques on agriculturally important plant viroids will be help for easy, sensitive ,economical and quick the viroid diagnosis procedures alternative to high cost diagnostic kits.

\section{ACKNOWLEDGEMENT}

The author is thankful to Dr. A.A.F.L.K. Perera and Mrs. W.B.S Fernando of the Genetics and Plant Breeding Division, Coconut Research Institute Sri Lanka, Ms. A.N.K. Perera of Department of Biotechnology of Wayamba University of Sri Lanka, Prof. J.Randles of Adelaide University of Australia and Mr. Preben Normann are acknowledged for their corporation for the study and guidance.

\section{REFERENCES}

Boom, R., C.J. Sol, M.M. Salimans, C.L. Jansen, P.M. Wertheim-van Dillen \& J. van der Noordaa. 1990. Rapid and simple method for the purification of nucleic acids. J Clin. Microbiol. 28, 495-503.

Dellaporta, S.L., J. Wood \& J.B. Hicks. 1983. A plant DNA minipreparation: version II. Plant Mol. Biol. Report. 1, 19-21.

Ding, B \& A. Itaya. 2007. Viroid: A Useful Model for Studying the Basic Principles of Infection and RNA Biology. Mol. Plant Microbe. 20, 7-20.

Feldstein, P.A., L. Levy, J.W. Randles \& R.A. Owens. 1997. Synthesis and two-dimensional electrophoretic analysis of mixed populations of circular and linear RNAs. Nucleic Acid Res. 25, 4850 - 4854.

Flores, R., C. Hernandez, A.E. Martinez de Alba, J.A. Daros \& F. Di Serio. 2005. Viroid and viroid-host interactions. Annu. Rev. Phytopathol. 43, 117139.

Hanold, D. 1993. Diagnostic methods applicable to viroids. In: Matthews, R.E.F. ed., Diagnosis of plant virus disease, Boco Raton., CRC Press, 295313.
Richard, H. 1998. Small scale extraction of nucleic acid from plant tissue. In: Richard, A.J.H. ed. Molecular tools for plant pathogen diagnosis. $3^{\text {rd }} \mathrm{Ed}$. University of Adelaide. 21-27.

Richard, H., L. Krake \& A. Rezaian. 1998. Gel electrophoresis for fractionation of nucleic acids. In: Richard, A.J.H. ed. Molecular tools for plant pathogen diagnosis. $3^{\text {rd }}$ Ed. University of Adelaide. 70-73.

Robert, E.F. 1998. RNA Methodologies: A Laboratory Guide for Isolation and Characterization, $2^{\text {nd }}$ ed., Academic Press. p. 448.

Roenhorst, J. W., R. P. T. Butôt, K. A. van Der Heijden, M. Hooftman \& van Zaayen. 2000. Detection of Chrysanthemum stunt viroid and Potato spindle tuber viroid by return-polyacrylamide gel electrophoresis. EPPO Bulletin 30, 453-456

Roger Hull. 2009. Comparative Plant Virology. 2nd Ed. Elsevier Academic Press publications. p. 376.

Schumacher, J., N. Meyer, D. Riesner \& H.L. Weidemann. 1986. Diagnostic procedure for detection of viroids and viruses with circular RNAs by "Return"-Gel Electrophoresis. J. Phytopathol. $115,332-343$.

Schumacher, J., J.W. Randles \& D. Riesner. 1983. A twodimensional electrophoretic technique for the detection of circular viroids and virusoids. Anal. Biochem. 135, 288-295.

Singh, R.P. 1991. Return-polyacrylamide gel electrophoresis gel electrophoresis for the detection of viroids, In Viroid and satellites: Molecular parasites at the frontier of life. CRC Press. London.

Tian, H., A.F. Huhmer \& J.P. Landers. 2000. Evaluation of silica resin for direct and efficient extraction of DNA from complex biological matrices in a miniaturized format. Anal. Biochem. 283, 175191.

Wijerathna, Y.M.A.M. 2012. Application of Biotechnology in Intra Cellular Pathogen Diagnostic of Coconut (Cocos nucifera L.) in Sri Lanka". Report on In-plant Training Programme. Wayamba University of Sri Lanka.

Wilkins, T.A. \& L.B. Smart. 1996. Isolation of RNA from plant tissue. In: Krieg, P.A. ed. A laboratory guide to RNA: isolation, analysis, and synthesis. New York, NY, Wiley-Liss, Inc. pp. 21-42. 